In $197034 \%$ of strains were resistant to tenance haemodialysis and did so without tetracycline, in $197146 \%$, in $197254 \%$, and significant alteration in blood pressure and in 1973 to date $35 \%$. It would seem there- body weight.-We are, etc., fore that in this area, at least, there has been no fall in the level of tetracycline-resistant Strep. pyogenes over the past four years. The majority of strains isolated continue to come from throat swabs, though many also come from skin sepsis and abscesses. Group B haemolytic streptococci show an even higher prevalence of tetracycline resistance$58 \%$ of 74 strains isolated so far this year (mainly from vaginal swabs) were resistant to this drug.

Whether the difference between Dr. Robertson's findings and mine is due to letter from Mr. J. W. Kyle and Dr. differences in the usage of tetracyclines in Jenkinson (29 September, p. 698) regarding the two areas is something on which I the treatment of depressed fracture in the cannot comment, but our results illustrate newborn by the use of a Malmstrom vacuum how widely divergent antibiotic sensitivity extractor.

patterns may be observed in different areas of the couniry.-I am, etc.,

Department of Laboratory Medicine, Ruchill Hospital, Glasgow

\section{Muscle Cramps during Maintenance} Haemodialysis

SIR,- - The benefits obtained by the use of dialysate with a high sodium content have been recorded by Dr. W. K. Stewart and Miss Laura W. Fleming. ${ }^{1}$ However, in reply to their letter (13 October, p. 107) we wish to establish the following points:

(1) A large increase in the weight gained by patients between dialyses is a consequence of using dialysate with a sodium concentration of $145 \mathrm{mmol} / \mathrm{l}$. Dr. Stewart and his colleagues in a study of nine patients have themselves reported a mean weight gain of $4.40 \mathrm{~kg}$. $^{1}$ We consider that weight increases of this magnitude are undesirable and, in particular, may constitute a further hazard to patients on home dialysis who, in our experience, frequently have difficulty in maintaining a constant post-dialysis "ideal" weight. The administration of Slow Sodium produced no significant change in the mean inter-dialysis weight gain.

(2) As the results presented in our paper (18 August, p. 389) were obtained from a double-blind trial of Slow Sodium on a group of patients on maintenance haemodialysis, the calculation of mean values inevitably obscured individual therapeutic successes and failures. For example, one patient recorded a reduction in the incidence of cramp from $73 \%$ to $13 \%$ and two patient who had noted cramp with the placebo ex perienced none at all while taking the sodium chloride preparation. Moreover, since the trial ended, several of the patients who noted no benefit from $140 \mathrm{mmol}$ of sodium (14 tablets of Slow Sodium) have apparently derived relief from cramp with an increased dosage. It may thus be possible to adjust the dose of Slow Sodium to the requirements of the individual patient.

(3) An increase in the sodium content of the Slow Sodium preparation would certainly be of value in reducing the number of tablets a patient may have to consume. We have found, however, that those patients subject to severe cramp require no persuasion to swallow the tablets.

(4) The administration of Slow Sodium reduced the frequency and severity of muscle cramps in a proportion of patients on main-
Department of Medicine,

Stewart, W. K., Fleming, L., W., and Manuel,
M. A., Proceedings of the European Dialysis and Transplant Association, 1972, 9, 111.

\section{Depressed Fracture in the Newborn}

This approach to the problem of depressed fracture was originally suggested in the 17th century by Hildanus ${ }^{1}$ and subsequently by Ambroise Paré, ${ }^{2}$ but in the latter case particularly in relation to battle injury.

In my experience all the depressed fractures which I have encountered in the newborn have, in fact, corrected themselves spontaneously and for this reason one would hesitate to defend the open reduction of such fractures. The use of the vacuum extractor, however, might be undertaken much more readily in case spontaneous reduction does not occur.-I am, etc.,

Worcester Royal Infirmary,

J. A. Chalmers Worcester 1 Fabry, W. (Guildhelmi
Hildani ${ }_{\text {Opera, p. 84. }}^{\text {Fabricius Hildanus), }}$ Frankfurt-am-Main,
Beyer, 1632. Beyer, 1632.

Paré, A., The Works of That Famous Chirugion Ambrose Parey, trans. T. Johnson, p. 234

\section{Penicillin in Leptospirosis}

SIR,-With reference to Dr. L. Clein's letter (11 August, p. 354), a couple of years ago we had an epidemic of leptospirosis in the Thames Valley area in the North Island of New Zealand. As a general practitioner in that area at the time I was most impressed with the efficacy of the following regimenprocaine penicillin, 5 mega units at once followed by $2 \frac{1}{2}-3$ mega units daily for the next few days and tailing off to 1.5 mega units for a total course of five to seven days. In most cases immediate improvement was dramatic, with relief of the worst symptoms within 12-24 hours. In one or two penicillinsensitive patients I did try tetracycline $\mathrm{lg}$ six-hourly with results that were no better than with no treatment at all.

As far as I am concerned, there is no question about the efficacy of high-dosage penicillin and I have many grateful farmers to back this statement. All diagnoses were proved serologically.-I am, etc.,

Waikato Hospital,

H. NICHOLLS Hew Zealand

\section{Strange Encounter}

SIR,-Dr. J. C. Kelsey, in his Personal View (13 October, p. 104), refers to "Baron Munchausen" as a fictional character, a mistaken belief which I am sure I shared before I happened to meet his descendant, the present baron.
University of Aberdeen,
On a quiet country road near Hanover an Alsatian dog nearly ran under my staff car, to the alarm of its owner, a youngish man on a push-bike. A little later he came up as I was looking at a picturesque schloss near the village of Apelern. I asked him who owned the castle and he told me it was Baron von Münchausen. When I said something about being surprised to learn that such a person really existed, he placed a hand on his chest and humorously proclaimed, "Ich bin es." Our brief chat about his famous ancestor was just a little marred for me by my ignorance of the German for "tall stories," and by having consequently had to settle for the less courteous lüge (lies).

In fact, the hero of the stories, Hieronymus Karl Friedrich, Freiherr von Münchausen (1720-97), who soldiered in the Brunswick Regiment, was renowned for his after-dinner stories, which he told with a perfectly straight face. It has been said that his life was much saddened after his retirement from the Army when a Hanoverian author, Rudolf Erich Raspe, published his stories and virtually presented him to the world as its best-known liar.

Herr Herbert Hagel, who drove my staff car for some five years in Germany with the élan and skill with which he drove his tank in Russia, assured me that he recognized, from his school books, that the young baron whom we met that day possessed the typical Münchausen facies.-I am, etc.,

Edinburgh

FRANK RICHARDSON

\section{Points from Letters}

\section{"No Smoking" Ignored}

Dr. SYBIL M. RIChaRds (London N.W.11) writes: I have recently paid three visits (non-medical) to a friend in a London teaching hospital and in spite of notices banning smoking all over the corridors and wards, I found patients and visitors smoking on each occasion. When I drew the attention of three visitors at the next bed to the notices I was told it was no business of mine and on appealing to the staff nurse I received a stony glare and no reply. Several patients heard what I had said and told me that smoking often occurs quite openly during the night. ...

\section{Prescription Charge Anomalies}

Dr. C. LIPP (Sheffield) writes: Since when did o someone suffering from pernicious anaemia and on Cytamen or Neocytamen injections not have to pay for their prescriptions charges (Dr. D. W. Smith, 6 October, p. 52)? I do not find such disease noted on Page 1 of EC 91.

\section{Injecting Hydroceles-an Unproved}

Treatment?

Dr. R. G. APTHORPE (Halesworth, Suffolk) writes:

I hasten to back up Mr. G. E. Moloney's plea that injection treatment of hydroceles should be used as routine (20 October, p. 170). When I was in general practice in Luton I treated them by aspirating the fluid under a local anaesthetic and then changing the syringe and injected $2 \mathrm{ml}$ quinine and urethane. This is a painless procedure. The fluid would seemingly re-collect, but after a second aspiration and injection it did not recur. I used to preach the doctrine whenever I could, but no one paid any attention. Likewise the patients seemed to think an operation and stay in hospital was a more exciting method of cure and latterly I gave up the battle and sent them off to swell the hospital waiting lists ... , .
}

.

